\title{
Anterior Tongue Neoplasm
}

National Cancer Institute

\section{Source}

National Cancer Institute. Anterior Tongue Neoplasm. NCI Thesaurus. Code C6062.

A benign or malignant neoplasm that affects the anterior portion of the tongue. 